\title{
The effects of age at correction of aortic coarctation and recurrent obstruction on adolescent patients: MRI evaluation of wall shear stress and pulse wave velocity
}

Joe F. Juffermans ${ }^{1 *}$ D, Ineke Nederend ${ }^{2}$, Pieter J. van den Boogaard ${ }^{1}$, Arend D. J. ten Harkel ${ }^{2}$, Mark G. Hazekamp ${ }^{3}$, Hildo J. Lamb ${ }^{1}$, Arno A. W. Roest ${ }^{2}$ and Jos J. M. Westenberg ${ }^{1}$

\begin{abstract}
Background: Coarctation patients before curative reconstruction are exposed to abnormal flow patterns which potentially could cause wall deterioration. This study evaluated the effect of age at correction on the pulse wave velocity (PWV) and peak wall shear stress (WSS) in adolescent patients with corrected coarctation. Effects of valve morphology and presence of reobstruction were also evaluated.

Methods: Twenty-one patients aged $13.7 \pm 2.6$ years (mean \pm standard deviation) were included (bicuspid aortic valve, $n=14$; reobstruction, $n=9$ ). Mean age at correction was $1.0 \pm 1.8$ years. PWW was determined from two hightemporal through-plane phase-contrast magnetic resonance imaging (MRI) acquisitions, for two segments: ascending aorta plus aortic arch and descending aorta. WSS was determined from four-dimensional flow MRI. Peak WSS over five systolic phases was determined for ascending aorta, aortic arch, and descending aorta.

Results: Patients with tricuspid aortic valve showed a significant correlation between the age at correction and descending aorta PWV $\left(r_{s}=0.80, p=0.010\right)$. Significant differences were found between patients without and with reobstruction for peak WSS in the aortic arch ( $3.9 \pm 1.3 \mathrm{~Pa}$ versus $6.5 \pm 2.2 \mathrm{~Pa}$, respectively; $p=0.003)$ and descending aorta (5.0 \pm 1.3 Pa versus $6.7 \pm 1.1 \mathrm{~Pa}$, respectively; $p=0.005$ ).

Conclusions: A prolonged period of abnormal haemodynamic exposure may result in increased aortic wall stiffening. The increased peak WSS as results of a reobstruction possibly promotes different disease progression, which endorse longitudinal follow-up examination of corrected coarctation patients.
\end{abstract}

Keywords: Adolescent, Aortic coarctation, Bicuspid aortic valve, Magnetic resonance imaging, Pulse wave analysis

\section{Key points}

- Coarctation correction age correlates with descending aorta pulse wave velocity in patients with tricuspid aortic valve.

- Recurrent obstruction induces higher peak wall shear stress in the aortic arch.

- Recurrent obstruction induces higher peak wall shear stress in the descending aorta.

\footnotetext{
* Correspondence: J.F.Juffermans@lumc.nl

'Department of Radiology, Leiden University Medical Center, Albinusdreef 2, 2333 ZA Leiden, the Netherlands

Full list of author information is available at the end of the article
}

\section{Background}

Aortic coarctation $(\mathrm{CoA})$ is a congenital obstruction of aorta [1-3], typically located just distally from the aortic arch [2-7]. With a prevalence of approximately 3 to 4 per 10,000 live births [7-9], CoA accounts for 5 to $8 \%$ of all congenital heart defects $[1-3,6]$. The most commonly associated abnormality is a bicuspid aortic valve (BAV), with a prevalence rate between 60 and $85 \%$ in patients with CoA [3-6, 8]. After curative reconstruction, patients are at risk to develop late hypertension and residual or recurrent obstruction [3, 10], the latter with a prevalence up to $30 \%$ [4]. 
Before reconstruction, the local aortic narrowing results in an increased afterload of the heart and a pressure gradient over the obstruction with associated formation of abnormal aorta flow patterns [1]. The viscous friction of the blood (i.e., the haemodynamic load) on the vessel wall regulates the endothelium lining properties, which by high wall shear stress (WSS) promotes vascular dilatation and remodelling [11]. Additionally, more collagen tissue and less smooth muscle fibres are observed within the aortic wall proximally towards the lesion compared to distally [12]. It is unclear whether the abnormal haemodynamic situation prior to the correction already causes aortic wall deterioration [13]. Knowledge of this causality is important in order to identify the ideal time for intervention [7]. Paradoxically, an older age of curative CoA reconstruction is associated with an increased risk of left ventricular hypertrophy and late hypertension [14] but also lower rates of reintervention on the descending aorta [7]. However, for patients younger than the age of five, the risk of reintervention is decreased for patients who had the initial repair before the age of 1 year [7].

In the literature, phase-contrast magnetic resonance imaging (MRI), also known as velocity-encoded or flow MRI, has been applied as innovative application to analyse aortic flow haemodynamics in healthy controls and patients. For example, within CoA patients, flow MRI is utilised to examine the pulse wave velocity (PWV), a surrogate marker for the aortic wall stiffness, and WSS. These studies [15-19] demonstrated an increased aortic arch PWV in surgically corrected CoA patients compared to healthy controls. For WSS, both increased [20] and decreased [18] time-averaged WSS were observed in CoA patients compared to healthy control. Surprisingly, only one article was found describing the effect of age at curative reconstruction on the PWV and WSS [19]. However, no discrimination was made on the aorta valve morphology and absence of recurrent obstruction between these patients when evaluating the effect of age at curative reconstruction.

Therefore, this study was aimed at evaluating the effect of age at curative reconstruction on the aortic wall stiffness expressed as PWV and the haemodynamic load expressed as peak WSS in adolescent patients with corrected CoA. Also, effects of valve morphology and presence of reobstruction were evaluated. Our hypothesis is that a correction for CoA patients at younger age may result in less aortic wall stiffening and lower peak haemodynamic load, as a result of the shorter period of hypertension in the arterial system upstream of the coarctation site and exposure to abnormal flow patterns distal to the obstruction.

\section{Methods}

\section{Study population}

This prospective study protocol was approved by the Medical Ethics Committee of the Leiden University
Medical Center (P14.095), and informed consent was signed by both parents/guardians of all subjects. Children with chromosomal disorder were excluded to preserve homogeneity of the population. Thirty-two patients after surgical CoA repair participated in the study and underwent a cardiovascular magnetic resonance imaging (MRI) examination. These patients were also included in a previous study with the aim to investigate the cardiac autonomic nervous system activity, cardiac function, and their relationship in children after CoA repair [21]. Eventually, eleven of them were excluded due to practical and emotional problems (e.g., patient movement and endurance) during the MRI. The included 21 patients were aged $13.7 \pm 2.6$ years (mean \pm standard deviation), including 12 patients with bicuspid aortic valve (BAV) and 9 patients with tricuspid aortic valve (TAV). Mean age at CoA correction was $1.0 \pm 1.8$ years, performed by end-toend anastomosis in 16, extended end-to-end anastomosis in 2, and subclavian flap in 1 patient. Only one patient, as result of a recurrent obstruction, underwent a reoperation using an autologous pericardial patch. None of the patients had a clinical indication for reintervention at the time of the MRI examination. The included patients were scanned between September 2015 and May 2016, and time between reconstruction and MRI was $12.6 \pm 3.0$ years.

The presence of an aortic reobstruction was determined based on the maximal flow velocity in the descending aorta, measured by a suprasternal transthoracic Doppler echocardiogram (VIVID 9, GE Healthcare, Norway) by a single observer (IN), supervised by an experienced clinician $(\mathrm{AH})$ in all patients. The acquired images were stored and analysed offline using the EchoPAC software version 113 (General Electric Healthcare, Horten, Norway). Based on this analysis, the presence of a reobstruction was determined, defined as a maximal flow velocity larger than $2.5 \mathrm{~m} / \mathrm{s}$ [22]. Using this criterion, the patient group was divided into two groups: twelve without and nine with recurrent obstruction.

\section{MRI acquisition}

The image acquisition consisted of two MRI throughplane phase-contrast MRI sequences to determine aortic PWV and one four-dimensional (4D) flow MRI sequence. MRI for all patients were performed on a 3-T scanner (Ingenia, Philips Healthcare, Best, The Netherlands) using a combination of both a FlexCoverage posterior coil in the table and a dStream Torso anterior coil, together providing up to 32-coil elements for signal reception. Concomitant gradient correction and local phase correction were performed from standard available scanner software.

The PWV was determined from high-temporal through-plane phase-contrast MRI using free breathing 
with retrospective electrocardiographic gating, for both the proximal aorta (ascending aorta plus aortic arch) and the descending aorta. This was accomplished by measuring the flow velocity through two planes positioned perpendicular to aortic centreline: the first plane intersecting both the ascending and thoracic descending aorta and the second plane intersecting the abdominal descending aorta, defined as proximal PWV and diaphragmatic PWV, respectively. The proximal PWV MRI sequence parameters were as follows: velocity encoding of $200-300 \mathrm{~cm} / \mathrm{s}$ in feet-head direction, acquired temporal resolution $8.4 \mathrm{~ms}$, reconstructed temporal resolution $4.1 \mathrm{~ms}(171 \pm 24$ phases), echo time $2.3 \mathrm{~ms}$, repetition time $4.2 \mathrm{~ms}$, flip angle $20^{\circ}$, field of view $350 \times$ $350 \times 8 \mathrm{~mm}$, and acquired spatial resolution $2.8 \times 2.8 \times$ $8.0 \mathrm{~mm}$. Acquisition time and heart rate were on average $75 \pm 10 \mathrm{~s}$ and $83 \pm 12$ beats per min, respectively. Diaphragmatic PWV MRI sequence parameters were as follows: velocity encoding of $150-250 \mathrm{~cm} / \mathrm{s}$ in feet-head direction, acquired temporal resolution $8.6 \mathrm{~ms}$, reconstructed temporal resolution $4.1 \mathrm{~ms}$ ( $167 \pm 23$ phases), echo time $2.4 \mathrm{~ms}$, repetition time $4.3 \mathrm{~ms}$, flip angle $20^{\circ}$, field of view $350 \times 350 \times 8 \mathrm{~mm}$, and acquired spatial resolution $2.8 \times 2.8 \times 8.0 \mathrm{~mm}$. Acquisition time and heart rate were on average $78 \pm 12 \mathrm{~s}$ and $84 \pm 11$ beats per min, respectively.

The aortic 4D flow MRI sequence used a hemidiaphragm respiratory navigator, a retrospective ECG gating, and a standard non-symmetrical four-point velocity encoding. Sequence parameters were as follows: velocity encoding of $200-350 \mathrm{~cm} / \mathrm{s}$ in four directions, acquired temporal resolution $34.4 \mathrm{~ms}$, reconstructed temporal resolution $29.2 \mathrm{~ms}$ ( $26 \pm 4$ phases), echo time $2.4 \mathrm{~ms}$, repetition time $4.3 \mathrm{~ms}$, flip angle $10^{\circ}$, field of view $350 \times$ $350 \times 52.5-72.5 \mathrm{~mm}$, acquired spatial resolution $2.5 \times$ $2.5 \times 2.5 \mathrm{~mm}$, segmentation factor 2 , and sensitivity encoding factor 2 in anterior-posterior direction. Acquisition time was on average $4.9 \pm 0.7 \mathrm{~min}$ excluding the respiratory compensation. Due to the acceptance window of the respiratory navigator, the actual acquisition time in the scanner approximately doubled.

\section{Image analysis}

The image analysis consisted of two parts to determine aortic PWV and the WSS. In order to obtain the PWV, the acquired proximal PWV and diaphragmatic PWV images firstly were analysed using the in-house developed software MASS (LUMC). This software was used to perform velocity mapping and to measure the length of both aortic segments on a multislice survey of the aorta. Lastly, these quantifications were imported into an in-house developed MATLAB-based application to determine the PWV of the proximal and descending aorta, using the foot-to-foot method (Fig. 1). In all subjects, the PWV image analysis was performed by a single observer (IN) with over 3-year experience in cardiovascular MRI, supervised by an experienced researcher (JW) with over 20 years' experience in cardiovascular MRI. Additionally, the PWV ratio was also derived from these values, defined as the descending aorta PWV divided by the proximal aortic PWV. This PWV quantification method was previously validated and described in more detail by Grotenhuis et al. [23].

From 4D flow MRI, the WSS was determined using CAAS MR Solutions v5.0 (Pie Medical Imaging, Maastricht, The Netherlands), assuming a constant blood viscosity of $4 \mathrm{mPa}$. This software was used to compute the WSS over five time phases and three consecutive aortic segments (Fig. 1): the aortic root plus the ascending aorta, the aortic arch, and the descending aorta (respectively; from the aortic valve to the brachiocephalic artery, from the brachiocephalic artery up and including the left subclavian artery, and from the subclavian artery to the abdominal descending aorta at the level of measurement of the diaphragmatic PWV). This was accomplished by firstly segmenting the aorta on a combined weighted magnitude and velocity image for all five available time phases, incorporating only the aorta and excluding the main branches (e.g., the subclavian and carotid arteries). Secondly, the anatomical segmentation planes were manually placed and imported perpendicular to the aortic wall. From proximally to distally on the aorta, these planes were positioned at the aortic valve, proximally against the brachiocephalic artery, distally against the subclavian artery, and $10 \mathrm{~cm}$ caudal below the diaphragm. Thirdly, for the five available time phases and each anatomical segment, the maximal WSS was exported from CAAS. Lastly, these maxima over the five time phases were used to determine the peak WSS for each anatomical segment over all five time phases. The WSS image analysis was performed by a single observer (IN) in all patients. The applied method to determine the WSS in the five systolic time phases was previously described and validated on the reproducibility by van der Palen et al. [24].

\section{Statistical analysis}

The statistical analysis was performed using the SPSS v23 software (IBM, Chicago, IL, USA). Differences between groups were compared using the independent sample $t$ test or Mann-Whitney $U$ test, respectively used for parametric scale data or non-parametric scale and ordinal data. Correlations between variables within groups were evaluated using the Pearson $\left(r_{\mathrm{P}}\right)$ and Spearman rank $\left(r_{\mathrm{S}}\right)$ correlations, respectively used for parametric scale data or non-parametric scale and ordinal data. The Levene test was used to verify the equality of variance and Shapiro-Wilk test to verify the normality 

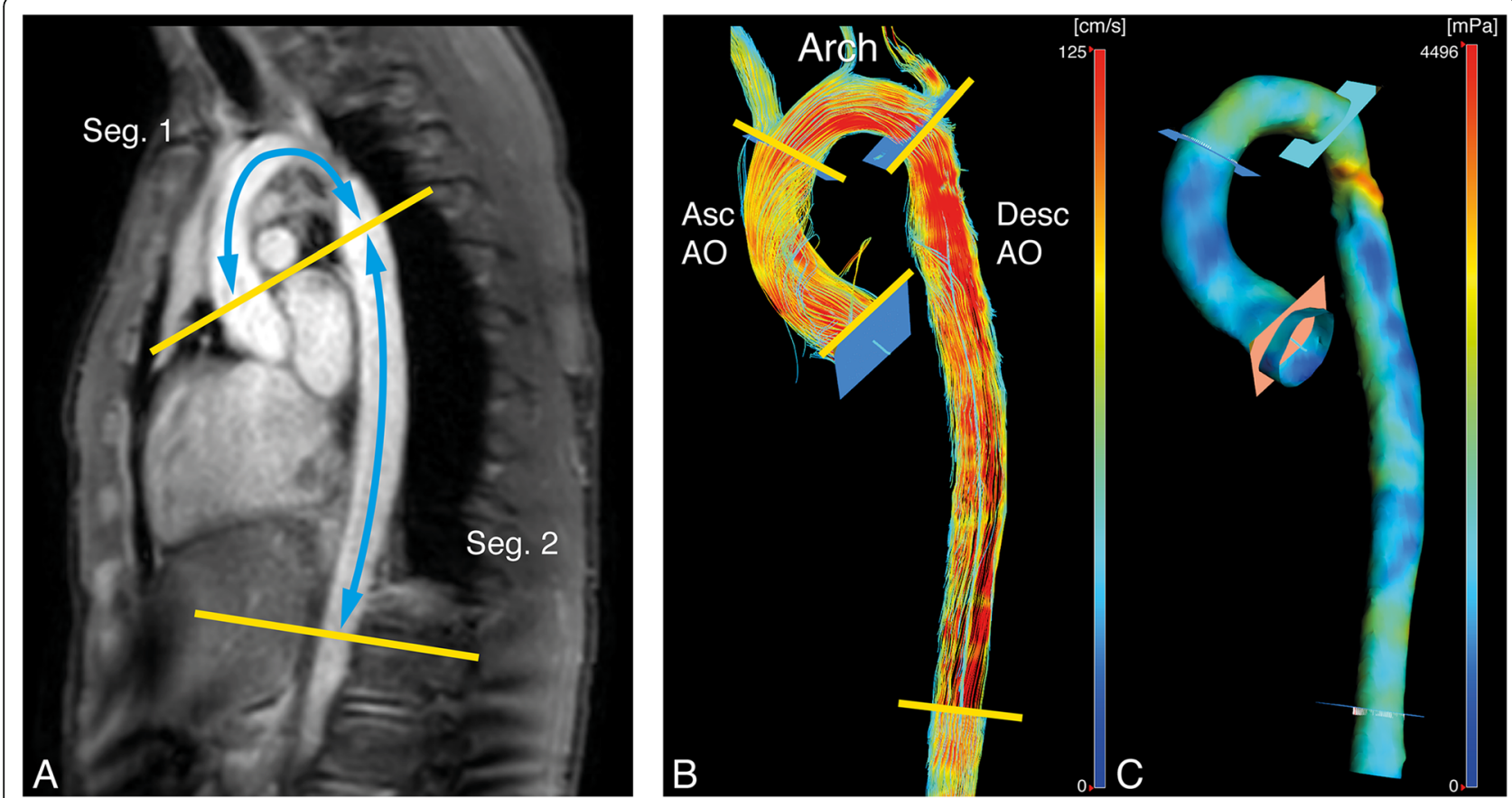

Fig. 1 Example of a patient aortic coarctation and tricuspid aortic valve without reobstruction. a Pulse wave velocity segments (Seg.): 1, proximal aorta; 2, descending aorta. b Wall shear stress segments: Asc AO, ascending aorta; Arch, aortic arch; Desc AO, descending aorta. c Three-dimensional magnitude wall shear stress map

of the data. The absolute correlation coefficient $\left(r_{\mathrm{P}}\right.$ or $r_{\mathrm{s}}$ ) was classified as follows: $0.30<|r|<0.50$, weak; $0.50<|r|<0.70$, moderate; $0.70<|r|<0.85$, good; and $|r|>0.85$, strong. All statistical tests were two-tailed, and a $p$ value of less than 0.05 was considered significant. Data will be presented as mean values with standard deviations.

\section{Results}

Characteristics of the CoA patients and subgroups are shown in Table 1. Non-significant correlations within the entire patient population $(n=21)$ were found between the following parameters: the age at correction and MRI, PWV in the proximal and descending aorta, PWV ratio, and peak WSS in the

Table 1 Patient and subgroup characteristics

\begin{tabular}{|c|c|c|c|c|c|}
\hline & Patients & TAV & BAV & No reobstruction & Reobstruction \\
\hline Populations size & 21 & 9 & 12 & 12 & 9 \\
\hline Age at reconstruction (years) & $1.0 \pm 1.8$ & $1.6 \pm 2.4$ & $0.5 \pm 1.1$ & $0.5 \pm 1.2$ & $1.6 \pm 2.4$ \\
\hline Age at MRI (years) & $13.7 \pm 2.6$ & $13.1 \pm 2.5$ & $14.1 \pm 2.7$ & $12.9 \pm 2.9$ & $14.7 \pm 1.7$ \\
\hline $\begin{array}{l}\text { Time between reconstruction } \\
\text { and MRI (years) }\end{array}$ & $12.6 \pm 3.0$ & $11.5 \pm 2.9$ & $13.5 \pm 2.8$ & $12.3 \pm 2.9$ & $13.1 \pm 3.3$ \\
\hline Body mass index $\left(\mathrm{kg} / \mathrm{m}^{2}\right)^{a}$ & $20.3 \pm 4.7$ & $18.7 \pm 1.8$ & $21.5 \pm 5.8$ & $20.3 \pm 5.8$ & $20.3 \pm 2.7$ \\
\hline Body surface area $\left(\mathrm{m}^{2}\right)$ & $1.5 \pm 0.3$ & $1.5 \pm 0.2$ & $1.6 \pm 0.3$ & $1.5 \pm 0.3$ & $1.6 \pm 0.3$ \\
\hline Gender (male/female) & $11 / 10$ & $2 / 7$ & $9 / 3$ & $5 / 7$ & $6 / 3$ \\
\hline PWV proximal aorta $(\mathrm{m} / \mathrm{s})$ & $4.8 \pm 1.4$ & $5.0 \pm 1.3$ & $4.7 \pm 1.5$ & $4.8 \pm 1.7$ & $4.9 \pm 0.9$ \\
\hline PWV descending aorta $(\mathrm{m} / \mathrm{s})$ & $3.7 \pm 0.8$ & $3.75 \pm 0.4$ & $4.1 \pm 1.1$ & $3.7 \pm 0.5$ & $4.2 \pm 1.2$ \\
\hline PWV ratio & $0.9 \pm 0.3$ & $0.8 \pm 0.2$ & $0.9 \pm 0.3$ & $0.9 \pm 0.3$ & $0.9 \pm 0.3$ \\
\hline Peak WSS ascending aorta (Pa) & $5.3 \pm 1.4$ & $4.8 \pm 1.1$ & $5.7 \pm 1.4$ & $4.9 \pm 0.9$ & $5.9 \pm 1.7$ \\
\hline Peak WSS aortic arch (Pa) & $5.0 \pm 2.1$ & $4.6 \pm 2.6$ & $5.3 \pm 1.8$ & $3.9 \pm 1.3$ & $6.5 \pm 2.3$ \\
\hline Peak WSS descending aorta $(\mathrm{Pa})$ & $5.7 \pm 1.4$ & $5.3 \pm 1.3$ & $6.0 \pm 1.5$ & $5.0 \pm 1.3$ & $6.7 \pm 1.1$ \\
\hline
\end{tabular}

Data presented as mean \pm standard deviation. BAV Bicuspid aortic valve, PWV Pulse wave velocity, TAV Tricuspid aortic valve, WSS Wall shear stress ${ }^{\text {a According to Dubois formula }}$ 


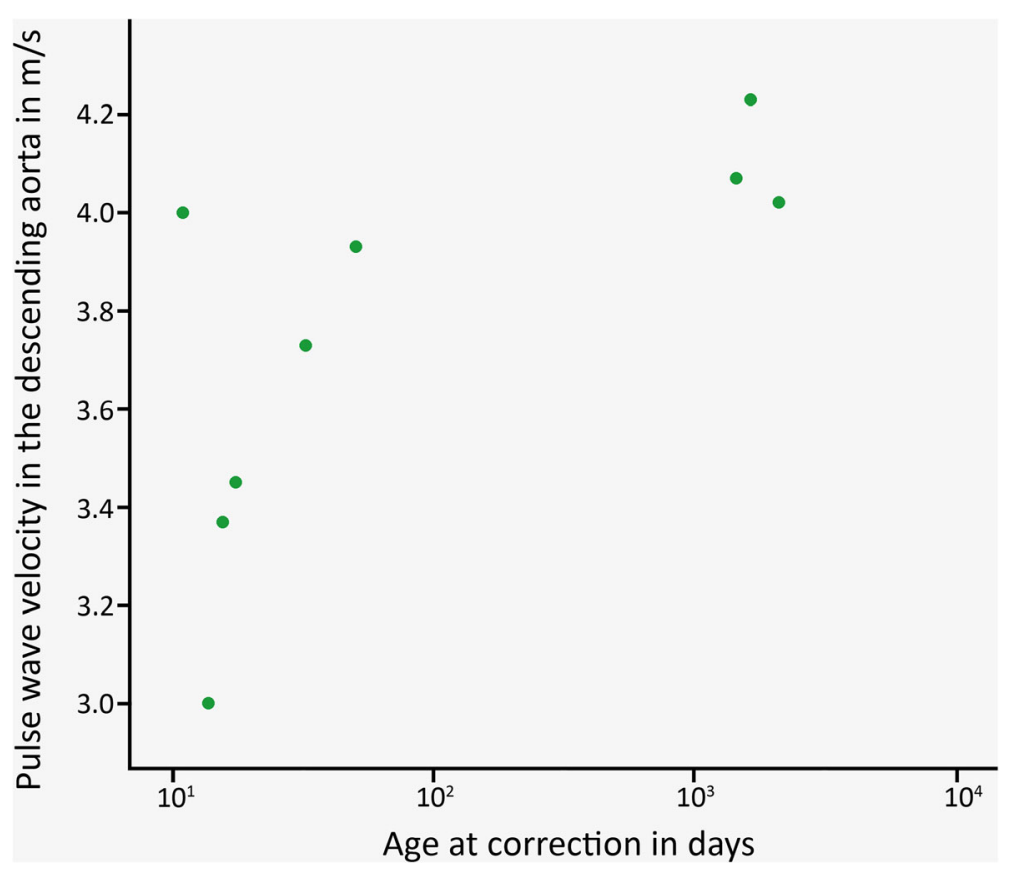

Fig. 2 Plot of the descending aorta pulse wave velocity over the age at correction for the tricuspid aortic valve patient subgroup

ascending aorta, aortic arch, and descending aorta. And, for the same parameters, non-significant group differences between the BAV and TAV subgroups were found (respectively, $n=12$ and $n=9$ ). For patients with a TAV, a significant good correlation was found between age at correction and descending aorta PWV ( $r_{\mathbf{s}}=0.80, p=0.010$, Fig. 2), indicating higher values of descending aorta PWV for patients with a TAV that underwent correction of CoA at an older age. Such a correlation was absent for patients with BAV. Between the subgroups without reobstruction and with reobstruction (respectively, $n=12$ and $n=9$ ), significant differences were found for the peak WSS in the aortic arch $(3.9 \pm 1.3 \mathrm{~Pa}$ versus $6.5 \pm 2.2$ $\mathrm{Pa}$, respectively; $p=0.003$ ) and descending aorta $(5.0 \pm 1.3 \mathrm{~Pa}$ versus $6.7 \pm 1.1 \mathrm{~Pa}$, respectively; $p=$ 0.005), indicating higher peak WSS values for patients with a reobstruction proximally and distally to the lesion. The statistical analysis within subgroups subdivided on both the aortic valve morphology and the presence of reobstruction was not performed, due to small population sizes within these subgroups. Examples of three-dimensional magnitude WSS maps of patients, subdivided on the aortic valve morphology and the presence of reobstruction, are shown in Fig. 3. The examples demonstrate higher peak WSS in the aortic arch and descending aorta for patients with reobstruction compared to those without reobstruction.

\section{Discussion}

In this study, the effect of age at curative reconstruction on the aortic wall stiffness expressed as PWV and the haemodynamic load by viscous friction on the arterial wall, expressed in peak WSS, was evaluated in adolescent patients with corrected CoA. Also, the effects of the aortic valve morphology and presence of reobstruction were evaluated. The main findings of this study were as follows: (1) a significant positive correlation between age at correction and PWV in the descending aorta for the TAV subgroup and (2) a significant difference in peak WSS in the aortic arch and descending aorta between the subgroup without reobstruction and the subgroup with reobstruction.

The observed positive correlation for TAV subgroup between the age at correction and descending aorta PWV suggests that a prolonged period of abnormal haemodynamic exposure may result in increased aortic wall stiffening. Specifically for TAV patients, this is in line with the hypothesis that for CoA patients, a curative reconstruction at a younger age will result in less wall stiffening, thus a lower PWV. This result should be interpreted with caution, since no correlation was found within the entire patient group nor in the BAV subgroup. The absence of a comparable correlation for these groups may be explained by the abnormal haemodynamics of BAV patients [25], potentially resulting in different disease progressions for both aortic valve morphologies. 

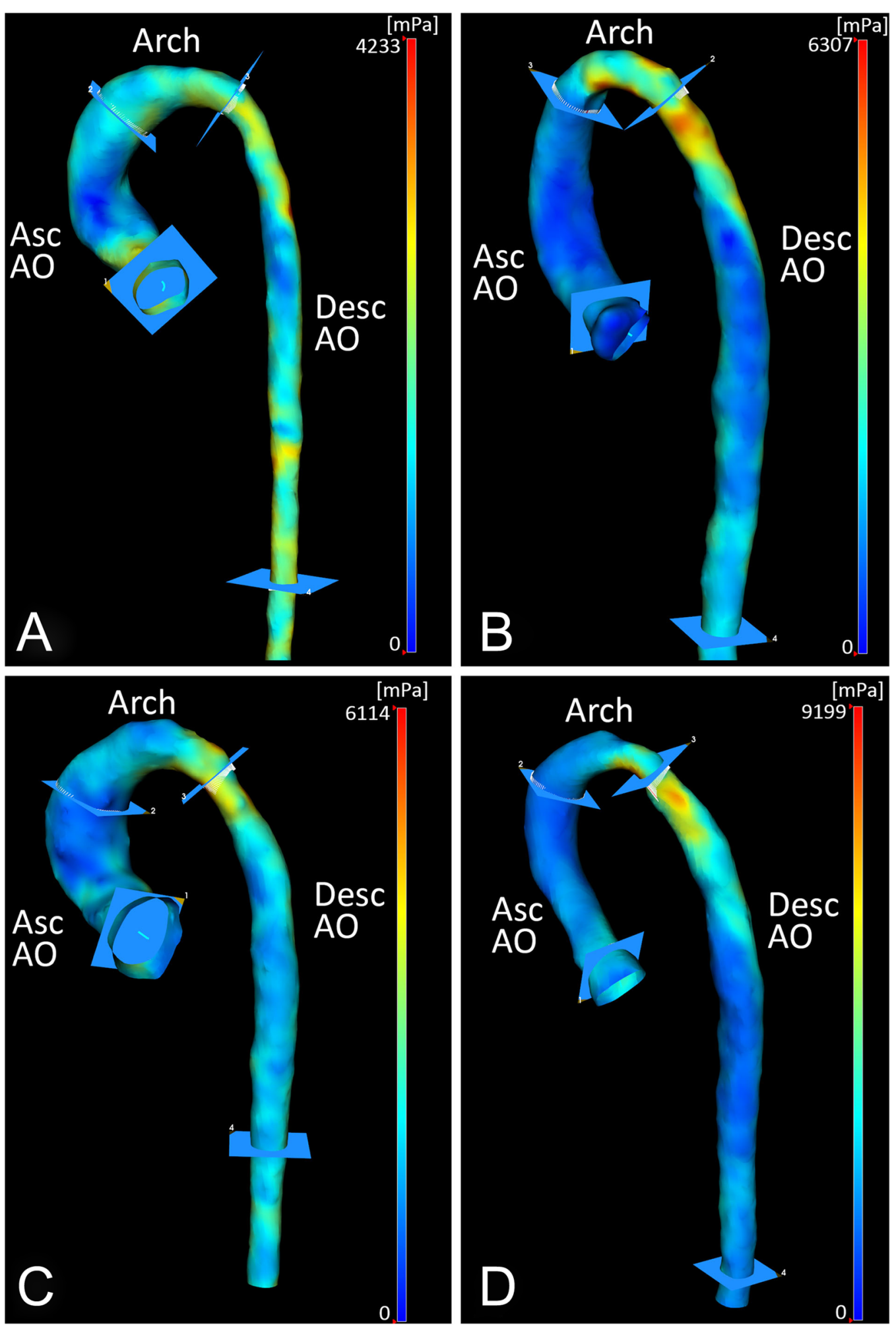

Fig. 3 Three-dimensional magnitude wall shear stress maps of patients with aortic coarctation subdivided on both the aortic valve morphology and the presence of reobstruction, incorporating the anatomical segments: Asc AO, ascending aorta; Arch, aortic arch; Desc AO, descending aorta. a Example of patient with tricuspid aortic valve without reobstruction. $\mathbf{b}$ Example of patient with tricuspid aortic valve with reobstruction. c Example of patient with bicuspid aortic valve without reobstruction. $\mathbf{d}$ Example of patient with bicuspid aortic valve with reobstruction 
Therefore, the significant finding in the TAV subgroup (notably, smaller in size than BAV subgroup) represents an evaluation of the CoA correction for patients selected on valve morphology. The abnormal haemodynamics of BAV patients results in more diversity of flow patterns within the entire patient population and subsequently may decrease the probability of detecting a significant effect. However, Voges et al. [19] observed a weak but significant positive correlation $(r=0.33)$ between the age at correction and the descending aorta PWV within their entire patient group, incorporating $16 \mathrm{BAV}$ and $35 \mathrm{TAV}$ patients. This effect presumably may be influenced by substantial larger group of TAV patients compared to BAV patients. Unfortunately, these authors did not statistically analyse this correlation separately within both aortic valve morphology subgroups.

The observed peak WSS differences in the aortic arch and descending aorta between the patients without and with reobstruction imply that local luminal narrowing results in an increased haemodynamic load on the aortic wall proximally and distally to the lesion. This effect was predominant within the aortic arch. Multiple studies indicated that endothelium lining properties are highly sensitive to the applied WSS on the vessel wall, which promotes adaptive dilation or structural remodelling of the artery wall during high WSS [11]. Therefore, different disease progression could potentially be expected for patient with and without postoperative obstructions. This endorses the initial curative reconstruction and longitudinal follow-up examination of corrected CoA patients. However, the surgical reconstruction is associated with the formation of abnormal postoperative aortic haemodynamic due to aorta compliance [8] and geometry $[26,27]$ modifications. For example, it has been demonstrated that the postoperative aortic arch geometry in CoA patients affects the PWV [27] and peak WSS magnitude and location [26]. Additionally, the presence of an aortic reobstruction was defined as a maximal flow velocity larger than $2.5 \mathrm{~m} / \mathrm{s}$. This criterion is arbitrary since peak flow velocity alone does not always discriminate patients without obstruction and those with obstruction [22]. Therefore, a single Doppler echocardiogram measurement will probably not be the decisive factor for reintervention in most clinical centres.

The present study has several limitations. Firstly, the number of CoA patients was limited by the available data, resulting in a relatively small population size and statistical power which also made the comparison of subgroups based on multiple patient characteristics difficult. Still, we were able to detect statistical significant findings for these limited group sizes. Secondly, the study only incorporated patients and no healthy controls, excluding the possibility to compare our results with reference values. Thirdly, the single-centre design limited the patient diversity, resulting in a relatively small variation of age at CoA correction. Fourthly, the severity of CoA prior to reconstruction is an important confounder. However, information of the severity of CoA was not available and therefore not involved in the statistical evaluation.

In conclusion, the association between the age at correction and descending aorta PWV for TAV patients suggests that a prolonged period of abnormal haemodynamic exposure may result in increased aortic wall stiffening. The increased peak WSS as results of a reobstruction possibly promotes different disease progression, which endorse longitudinal follow-up examination of corrected CoA patients.

\section{Abbreviations}

4D: Four-dimensional; BAV: Bicuspid aortic valve; CoA: Aortic coarctation; MRI: Magnetic resonance imaging; PWV: Pulse wave velocity; TAV: Tricuspid aortic valve; WSS: Wall shear stress

\section{Availability of data and materials}

All data obtained or analysed during this study are included in this published article.

\section{Funding}

JJ was financially supported by a grant from the Dutch Heart Foundation (Grant Number CVON2018-08-RADAR). IN was financially supported from the VU-AMS Revolving Research Fund.

\section{Acknowledgements}

The authors thank Gerrit Kracht from the Department of Radiology, Leiden University Medical Center, Leiden, the Netherlands, for having contributed with Fig. 1.

\section{Authors' contributions}

IN, AH, JW, and AR initiated the concept of the study. IN and AH participated in the Doppler echocardiogram data collection and analysis. JJ, IN, PB, and JW participated in the MRI data collection and analysis. JJ and JW performed the statistical analysis. JJ was the major contributor in writing the manuscript. All authors edited the manuscript. All authors reviewed and approved the final manuscript.

Ethics approval and consent to participate

This study protocol was approved by the Medical Ethics Committee of the Leiden University Medical Center (P14.095) and informed consent was signed by both parents and/or legal guardians of all subjects.

\section{Consent for publication}

The obtained data during this study was anonymised for research purposes. No personal data is included in this study.

\section{Competing interests}

The authors declare that they have no competing interests.

\section{Author details}

${ }^{1}$ Department of Radiology, Leiden University Medical Center, Albinusdreef 2, 2333 ZA Leiden, the Netherlands. ${ }^{2}$ Department of Pediatric Cardiology, Leiden University Medical Center, Albinusdreef 2, 2333 ZA Leiden, the Netherlands. ${ }^{3}$ Department of Cardiothoracic Surgery, Leiden University Medical Center, Albinusdreef 2, 2333 ZA Leiden, the Netherlands.

Received: 13 February 2019 Accepted: 17 May 2019

Published online: 20 June 2019

\section{References}

1. Nigro G, Russo V, Rago A et al (2012) Heterogeneity of ventricular repolarization in newborns with severe aortic coarctation. Pediatr Cardiol 33 302-306. https://doi.org/10.1007/s00246-011-0132-4

2. Xu J, Zhao H, Wang $X$ et al (2014) Accuracy, image quality, and radiation dose of prospectively ECG-triggered high-pitch dual-source CT angiography 
in infants and children with complex coarctation of the aorta. Acad Radiol 21:1248-1254. https://doi.org/10.1016/j.acra.2014.04.019

3. Turner DR, Gaines PA (2007) Endovascular management of coarctation of the aorta. Semin Intervent Radiol 24: 153-166. http://dx.doi.org/10.1055/s2007-980052

4. Karaosmanoglu AD, Khawaja RD, Onur MR, Kalra MK (2015) CT and MRI of aortic coarctation: pre-and postsurgical findings. AJR Am J Roentgenol 204: W224-W233. https://doi.org/10.2214/AJR.14.12529

5. Vergales JE, Gangemi JJ, Rhueban KS, Lim DS (2013) Coarctation of the aorta-the current state of surgical and transcatheter therapies. Curr Cardiol Rev 9:211-219. https://doi.org/10.2174/1573403X113099990032

6. Cardoso G, Abecasis M, Anjos R et al (2014) Aortic coarctation repair in the adult. J Cardiac Surg 29:512-518. https://doi.org/10.1111/jocs.12367

7. Brown ML, Burkhart HM, Connolly HM et al (2013) Coarctation of the aorta: lifelong surveillance is mandatory following surgical repair. J Am Coll Cardiol 62:1020-1025. https://doi.org/10.1016/j.jacc.2013.06.016

8. Baumgartner H, Bonhoeffer P, De Groot NM et al (2010) ESC Guidelines for the management of grown-up congenital heart disease (new version 2010). Eur Heart J 31: 2915-2957. https://doi.org/10.1093/eurheartj/ehq249

9. Reller MD, Strickland MJ, Riehle-Colarusso T, Mahle WT, Correa A (2008) Prevalence of congenital heart defects in metropolitan Atlanta, 1998-2005. J Pediatr 153:807-813. https://doi.org/10.1016/j.jpeds.2008.05.059

10. Wu LA, Chang Cl, Wang JK, Shih TT, Wu MH, Chen SJ (2013) Reference curves for the aortic area by age. Acad Radiol 20:16-24. https://doi.org/10. 1016/j.acra.2012.08.001

11. Davies PF (2009) Hemodynamic shear stress and the endothelium in cardiovascular pathophysiology. Nat Clin Pract Cardiovasc Med 6:16-26. https://doi.org/10.1038/ncpcardio1397

12. Sehested J, Baandrup U, Mikkelsen E (1982) Different reactivity and structure of the prestenotic and poststenotic aorta in human coarctation. Implications for baroreceptor function. Circulation 65:1060-1065. https://doi. org/10.1161/01.CIR.65.6.1060

13. Meadows J, Minahan M, McElhinney DB, McEnaney K, Ringel R (2015) Intermediate outcomes in the prospective, multicenter Coarctation of the Aorta Stent Trial (COAST). Circulation 31:1656-1664. https://doi.org/10.1161/ CIRCULATIONAHA.114.013937

14. Bocelli A, Favilli S, Pollini I et al (2013) Prevalence and long-term predictors of left ventricular hypertrophy, late hypertension, and hypertensive response to exercise after successful aortic coarctation repair. Pediatr Cardiol 34:620629. https://doi.org/10.1007/s00246-012-0508-0

15. Dijkema E, Slieker MG, Leiner T, Grotenhuis HB (2018) Arterioventricular interaction after coarctation repair. Am Heart J 201:49-53. https:/doi.org/10.1016/.j.ahj.2018.04.004

16. Ou P, Celermajer DS, Jolivet $O$ et al (2008) Increased central aortic stiffness and left ventricular mass in normotensive young subjects after successful coarctation repair. Am Heart J 155:187-193. https://doi.org/10.1016/j.ahj.2007.09.008

17. Quail MA, Short R, Pandya B et al (2017) Abnormal wave reflections and left ventricular hypertrophy late after coarctation of the aorta repair. Hypertension 69:501-509. https://doi.org/10.1161/HYPERTENSIONAHA.116.08763

18. Schäfer M, Morgan GJ, Mitchell MB et al (2018) Impact of different coarctation therapies on aortic stiffness: phase-contrast MRI study. Int J Cardiovasc Imaging 34:1459-1469. https://doi.org/10.1007/s10554-018-1357-6

19. Voges I, Kees J, Jerosch-Herold $M$ et al (2016) Aortic stiffening and its impact on left atrial volumes and function in patients after successful coarctation repair: a multiparametric cardiovascular magnetic resonance study. J Cardiovasc Magn Reson 18:56. https://doi.org/10.1186/s12968-016-0278-6

20. Frydrychowicz A, Markl M, Hirtler D et al (2011) Aortic hemodynamics in patients with and without repair of aortic coarctation: in vivo analysis by 4D flow-sensitive magnetic resonance imaging. Invest Radiol 46:317-325. https://oce.ovid.com/article/00004424-201105000-00005/HTML

21. Nederend I, de Geus EJC, Kroft LJM, Westenberg JJM, Blom NA, Ten Harkel ADJ (2018) Cardiac autonomic nervous system activity and cardiac function in children after coarctation repair. Ann Thorac Surg 105:1803-1808. https:// doi.org/10.1016/j.athoracsur.2018.01.084

22. Mühler E, Neuerburg JM, Rüben A et al (1993) Evaluation of aortic coarctation after surgical repair: role of magnetic resonance imaging and Doppler ultrasound. Br Heart J 70:285-290. https://doi.org/10.1136/hrt.70.3.285

23. Grotenhuis HB, Westenberg JJ, Steendijk P et al (2009) Validation and reproducibility of aortic pulse wave velocity as assessed with velocity-encoded MRI. J Magn Reson Imaging 30:521-526. https://doi.org/10.1002/jmri.21886

24. van der Palen RLF, Roest AAW, van den Boogaard PJ, de Roos A, Blom NA, Westenberg JJM (2018) Scan-rescan reproducibility of segmental aortic wall shear stress as assessed by phase-specific segmentation with 4D flow MRI in healthy volunteers. MAGMA 31:653-663. https://doi.org/10.1007/s10334-018-0688-6

25. Edlin J, Youssefi P, Bilkhu R et al (2018) Haemodynamic assessment of bicuspid aortic valve aortopathy: a systematic review of the current literature. Eur J Cardiothorac Surg 55:610-617. https://doi.org/10.1093/ejcts/ezy312

26. Olivieri LJ, de Zélicourt DA, Haggerty CM, Ratnayaka K, Cross RR, Yoganathan AP (2011) Hemodynamic modeling of surgically repaired coarctation of the aorta. Cardiovasc Eng Technol 2:288-295. https://doi.org/ 10.1007/s13239-011-0059-1

27. Ou P, Celermajer DS, Raisky O et al (2008) Angular (Gothic) aortic arch leads to enhanced systolic wave reflection, central aortic stiffness, and increased left ventricular mass late after aortic coarctation repair: evaluation with magnetic resonance flow mapping. J Thorac Cardiovasc Surg 135:62-68. https://doi.org/10.1016/j.jtcvs.2007.03.059

\section{Publisher's Note}

Springer Nature remains neutral with regard to jurisdictional claims in published maps and institutional affiliations.

\section{Submit your manuscript to a SpringerOpen ${ }^{\circ}$ journal and benefit from:}

- Convenient online submission

- Rigorous peer review

- Open access: articles freely available online

High visibility within the field

- Retaining the copyright to your article

Submit your next manuscript at $>$ springeropen.com 